\title{
АВТОМАТИЗИРОВАННАЯ СИСТЕМА ИЗМЕРЕНИЯ ФОНОВЫХ СОДЕРЖАНИЙ КОМПОНЕНТОВ АТМОСФЕРНОГО ВОЗДУХА
}

\section{1. Введение}

Для получения оперативной информации о состоянии атмосферного воздуха требуются автоматизированные стационарные и передвижные станции наблюдения. При составлении прогнозов состояния атмосферного воздуха конкретных регионов необходимо располагать данными о естественном фоновом уровне воздушных примесей, замеры которого затруднены влиянием антропогенных источников. Природным фоновым значением мы считаем среднюю концентрацию исследуемого вещества, которая измерена за длительный период на возможно максимальном расстоянии от источников загрязнения антропогенного характера. Фоновое содержание двуокиси серы в приземном слое атмосферы находится в пределах $\left.0,5-6 \mathrm{mkr} / \mathrm{m}^{3}{ }^{1}\right]$, двуокиси азота - $0,94-7,5 \mathrm{m \kappa r} / \mathrm{m}^{3}$ $[2,3]$.

Исходя из сказанного, при измерении фоновых концентраций должны соблюдаться следующие требования.

1. Так как в природе фоновые концентрации находятся вблизи порога чувствительности измерительных приборов, то для получения достоверных данных требуется накопление сигнала.

2. Для анализа зависимостей данных необходимы длительные непрерывные круглосуточные наблюдения за примесями атмосферного воздуха.

3. В сложных полевых условиях должны соблюдаться и обеспечиваться стабильные условия работы измерительных приборов.

4. В эксперименте необходимо одновременно достаточно часто регистрировать множество данных: концентрации исследуемых веществ, скорость ветра, направление ветра, температуру, влажность и т. д. для исключения непосредственного влияния конкретных эмиссионных источников на вывод фоновой составляющей.

5. Для последующего анализа и нахождения корреляционных зависимостей нужна запись больших массивов полученных данных на носитель информации.

Учитывая вышеизложенные особенности и требования к измерениям фоновых концентраций примесей атмосферного воздуха, в Институте химической и биологической физики (ИХБФ) АН ЭССР была создана автоматизированная система измерения двуокиси серы и окислов азота в атмосферном воздухе с одновременной регистрацией метеорологических параметров. Основными приборами системы служили серийные газоанализаторы фирмы «Antechnika Environment S.A.». Работой всех устройств системы управляла 16-разрядная микро-ЭВМ «УХАА-86», созданная также в ИХБФ АН ЭССР. 


\section{2. Описание системы}

Автоматизированная система измерения фоновых содержаний компонентов атмосферного воздуха состоит из флуоресцентного анализатора двуокиси серы AF-20 и хемилюминесцентного анализатора окислов азота $\mathrm{AC}-3$, приборов измерения метеорологических параметров и управляющей ЭВМ «УХАА-86» (рис. 1).

«УХАА-86» относится к профессиональным микро-ЭВМ. Основной микропроцессорный (МП) модуль управляет работой остальных модулей и обеспечивает передачу информации по системной шине между модулями, а также между микро-ЭВМ и экспериментальной установкой. Функции основного 16-разрядного МП 8086 расширены специализированными процессорами: сопроцессором 8087 для арифметических и тригонометрических вычислений с плавающей запятой и процессором ввода-вывода 8089. Связь оператора с микро-ЭВМ осуществляется с помощью клавиатуры видеотерминала, который соединен с МП модулем по стандартной последовательной линии RS232C. Микро-ЭВM «УХАА-86» адресует память емкостью до 1 Мбайта, а в данной системе достаточно иметь 256 кбайтов оперативной памяти.

Для хранения программ и данных системы в микро-ЭВМ «УХАА-86» применяются восьмидюймовые накопители на гибких магнитных дисках (НГМД). В данной системе применяются гибкие магнитные диски с двойной плотностью записи на одной стороне. Такой диск размещает более чем 500 кбайтов информации.

В системе применено матричное печатающее устройство MX-80 фирмы EPSON с графическим режимом печати, который используется при выводе суточных графиков,

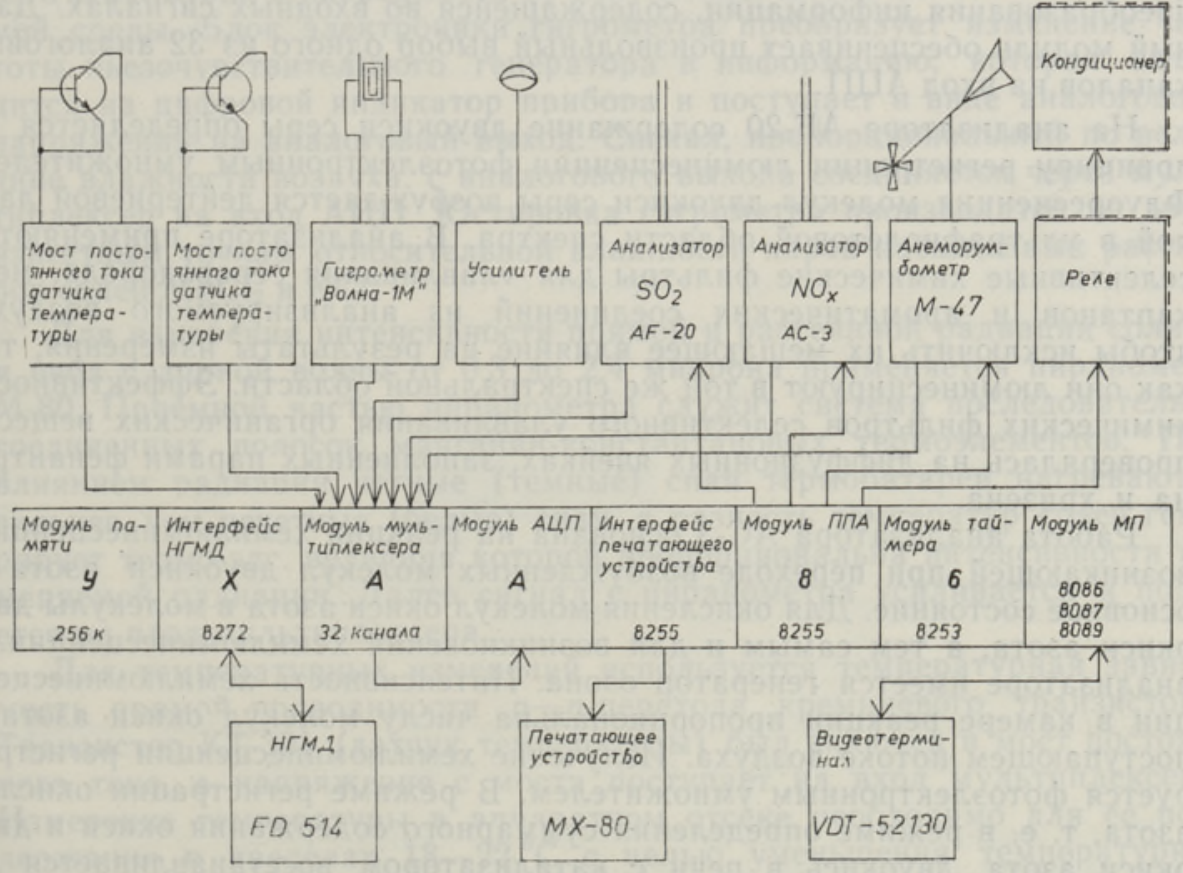

Рис. 1. Блок-схема автоматизированной системы измерения фоновых содержаний компонентов атмосферного воздуха, 
Названные модули и устройства позволяют использовать «УХАА-86» как универсальную ЭВМ с операционной системой (ОС) одного пользователя СР/M-86 или с мультипрограммными операционными системами «Concurrent CP/M» и «Concurrent DOS». Благодаря этим OC на микро-ЭВМ «УХАА-86» используется весь обширный фонд программ, созданных для МП 8086.

Модули автоматической системы измерения загрязненности воздуха к микро-ЭВМ «УХАА-86» созданы для управления системой и сбором информации в реальном масштабе времени. Подсчет реального времени суток происходит в модуле таймера. Для подсчета секунд, минут и часов применены соответственно три счетчика интегрального программируемого таймера 8253.

В модуле параллельного периферийного адаптера (ППА) для сопряжения с различными устройствами применен интегральный ППА 8255 A, имеющий 24 линии ввода-вывода, которые могут быть запрограммированы в соответствии с используемыми устройствами. Выходные регистры ППА 8255 А управляют режимами работы газоанализаторов, анеморумбометра и кондиционеров. Информация о направлении ветра в параллельном коде поступает на входной регистр ППА.

Для измерения аналоговых сигналов системы применяется интегрирующий аналого-цифровой преобразователь (АЦП). Данный АЦП с двухтактным интегрированием преобразует входное напряжение во временные интервалы, которые затем замеряются реверсивным счетчиком. Так как время одного такта интегрирования выбрано 20 мс, то производится эффективное подавление помех от электросети 50 Гц. На входе АЦП имеется усилитель программируемым коэффициентом усиления на 6 пределов. Преимуществом данного модуля АЦП является еще и то, что его аналоговая часть схемы изолирована от цифровой части.

Модуль релейного мультиплексера предназначен для передачи аналогового сигнала с выбранного входа на общий выход без какого-либо преобразования информации, содержащейся во входных сигналах. Данный модуль обеспечивает произвольный выбор одного из 32 аналоговых каналов на вход АЦП.

На анализаторе AF-20 содержание двуокиси серы определяется по принципу регистрации люминесценции фотоэлектронным умножителем. Флуоресценция молекул двуокиси серы возбуждается дейтериевой лампой в ультрафиолетовой области спектра. В анализаторе применяются селективные химические фильтры для vлавливания сероводорода, меркаптанов и ароматических соединений из анализируемого воздуха, чтобы исключить их мешающее влияние на результаты измерения, так как они люминесцируют в той же спектральной области. Әффективность химических фильтров селективного улавливания органических веществ проверялась на диффузионных ячейках, заполненных парами фенантрена и хризена.

Работа анализатора АC-3 основана на реакции хемилюминесценции, возникающей при переходе возбужденных молекул двуокиси азота в основное состояние. Для окисления молекул окиси азота в молекулы двуокиси азота, а тем самым и для возникновения хемилюминесценции, в анализаторе имеется генератор озона. Интенсивность хемилюминесценции в камере реакции пропоршиональна числу молекул окиси азота в поступающем потоке воздуха. Излученне хемилюминесценции регистрируется фотоэлектронным умножителем. В режиме регистрации окислов азота, т. е. в режиме определения суммарного содержания окиси и двуокиси азота, двуокись в печи с катализатором восстанавливается до окиси, а затем измеряется суммарная концентрация анализируемой окиси азота и восстановленной.

Регулярная проверка калибровки газоанализаторов производится по 
эталонным источникам газов двуокиси серы и окиси азота соответственно. Эталонным источником двуокиси серы является тефлоновая диффузионная ячейка, заполненная жидкой двуокисью серы, периодическое взвешивание которой в процессе калибрования определяет точное диффундированное количество двуокиси серы. Эталонирование анализатора окислов азота производится с помощью баллона со смесью окиси азота в азоте.

Для программного управления газоанализаторами они дополнены соответствующей логикой переключения режимов измерения и режимов нулевого уровня. Управление режимами газоанализаторов производится через модуль ППА. Аналоговый сигнал, пропорциональный по величине концентрации исследуемого газа, подается в интегрирующий АЦП через 32-канальный мультиплексер.

Измерение скорости и направления ветра производится при помощи анеморумбометра M-47. При вращении вертушки датчика ветра в его генераторе индуцируется переменное напряжение, пропорциональное по величине скорости вращения вертушки. Напряжение от генератора датчика скорости ветра через выпрямитель поступает на вход модуля мультиплексера и далее в АЦП.

Для измерения направления ветра в анеморумбометре M-47 применен принцип синхронной сельсинной передачи поворота флюгарки. Сельсин-датчик электрически соединен с сельсином-приемником, на оси которого закреплена стрелка шкалы. На ось сельсина-приемника был прикреплен диск с отверстиями в пятиразрядном коде Грея. Информация об угловом расположении флюгарки с пяти фотодиодов поступает на вход модуля ППА. Этот же модуль управляет переключением режимов измерения анеморумбометра.

Для измерения относительной влажности воздуха применяется цифровой гигрометр «Волна- $1 M$ ». Принцип действия гигрометра основан на измерении резонансной частоты колебаний пьезосорбционного кварцевого резонатора в зависимости от относительной влажности анализируемой среды. Блок электроники гигрометра преобразует изменение частоты пьезочувствительного генератора в информацию, которая выводится на цифровой индикатор прибора и поступает в виде аналогового напряжения на аналоговый выход. Сигнал, пропорциональный по величине влажности возлvха, с вналогового выхода соединяется через мультиплексер на вход АЦП. Юстировка гигрометра производится по двум известным точкам относительной влажности паров насыщенных растворов солей $\mathrm{MgCl}_{2}$ и $\mathrm{KCl}$.

Для измерения интенснвности прямой и рассеянной радиации солнца и неба с длиной волны от 0,3 до 2,4 микрона применяется пиранометр M-80. Приемной частью пиранометра служит система последовательно соединенных полосок манганин-константановых термоэлементов. Под влиянием радиации четные (темные) спаи термобатареи нагреваются сильнее, чем нечетные (белые) спаи, а разность температур спаев генерирует термо-эдс. величина которой пропорциональна интенсивности измеряемой радиации. Далее сигнал с пиранометра усиливается и подается на вход мультиплексера.

Для температурных измерений используется температурная зависимость прямой пповодимости $p-n$-перехода кремниевого транзистора. Транзистор КТ-301 (датчик темпепатуры) был включен в мост постоянного тока. а напряжение с моста поступает на вход мультиплексера. Измерение температуры в аппапатном отсеке пеобхолимо для ее подлержания в пределах $18-22^{\circ} \mathrm{C}$ с целью уменьшения температурной ошићки приборов.

Для управления совместной раплтой всей аппапатупы системы cocтавлена специальная программа VSP на языке MBASIC. Программа 
VSP работает в реальном масштабе времени и для подсчета времени суток используется модуль таймера реального времени, а учет суток и месяцев производится программно, т. е. программа VSP содержит в себе программный календарь на один год. Запуск программы начинается в режиме диалога машина-экспериментатор для начальной установки времени суток и даты.

Измерительно-управляемая часть программы начинается с проверки нулевого уровня газоанализаторов. В ходе эксперимента нулевой уровень проверяется ежечасно и данные корригируются на дрейф нуля. Ход измерений приводится на экране видеотерминала, где изображаются происходящие действия и результаты мгновенных измерений. Десятиминутные усредненные результаты измерений концентрации двуокиси серы, окислов азота (суммарные), окиси и двуокиси азота, направления и скорости ветра, относительной влажности воздуха, интенсивности солнечной радиации, наружной температуры воздуха, температуры внутри лаборатории выводятся на экран в виде таблицы. Усредненные результаты этих же параметров за каждый час, за три часа и за сутки печатаются на принтере MX-80.

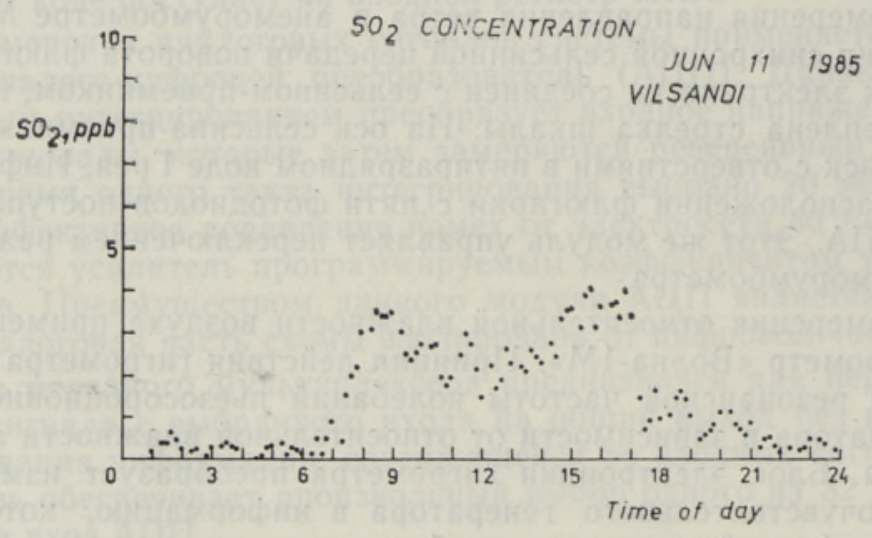

Рис. 2. Пример суточного графика концентрации двуокиси серы.

По окончании суток в 24.00 часа программа VSP выводит измеренные суточные данные в виде графиков на печатающее устройство (пример графика содержания двуокиси серы см. на рис. 2) и записывает их в файл данных на гибком магнитном диске. Название файла данных за каждые сутки содержит число, месяц, год, что облегчает дальнейшую сортировку и обработку. Данные записываются на односторонний гибкий магнитный диск одинарной плотности, чтобы запись была более надежной. На такой диск помещаются файлы данных за 30 суток, а на диск двойной плотности в двое больше. После записи файла данных меняется число месяца и продолжаются измерения примесей воздуха уже за следующие сутки.

\section{3. Использование системы автоматизированного измерения двуокиси серы и окислов азота в полевых условиях}

Вышеописанная система определения концентраций двуокиси серы и окислов азота была применена в полевых условиях различных регионов Эстонской ССР $\left[{ }^{4}\right]$. Для этого под передвижную лабораторию была переоборудована машина повышенной проходимости ГАЗ-66. 
Лаборатория имела свой мотор-генератор для собственного снабжения электроэнергией. По возможности, электроэнергия в лабораторию подавалась из стаңионарной сети, так как использование генератора требует дополнительных мер по предотвращению влияния выхлопных газов мотора на результаты измерений. Стабилизация сетевого напряжения для измерительных и управляющих приборов осуществлялась стабилизатором переменного тока «ORION KS1834/S». Tемпература в аппаратном отсеже регулировалась тремя кондиционерами.

На крышу машины были закреплены четыре мачты. Исследуемый воздух в анализаторы газов поступал с высоты 6 м по тефлоновым трубкам, защищенным от солнечной радиации, а датчики ветра находились на второй мачте высотой 9 м от поверхности земли. Датчик относительной влажности воздуха находился на третьей мачте под двойным куполом с отражающим экраном. Купол датчика гигрометра был предназначен для защиты прямого воздействия солнечных лучей и дождя. Датчик интенсивности суммарной радиации был прикреплен на отдельную мачту.

Для фоновых измерений требуется высокая чувствительность аппаратуры. Чувствительность описанной системы была определена экспериментально измерением воздуха, очищенного от примесей. Оказалось, что трехкратная среднеквадратичная ошибка $3 \sigma$ равна $0,2 \mathrm{ppb}\left(0,524 \mathrm{мкг} / \mathrm{m}^{3}\right)$ при двухчасовом усреднении данных. Таким образом, предельная чувствительность системы при определении сернистого газа в воздухе получена в 10 раз выше, чем гарантируется фирмой «Antechnika Environment S.A.» для флуоресцентного газоанализатора AF-20. Повышение чувствительности получено:

1) накоплением сигнала;

2) периодическим измерением и учетом дрейфа нуля газоанализатора;

3) поддержанием температуры приборного отсека в пределах 18 $22^{\circ} \mathrm{C}$ для уменьшения температурного влияния на измерительную систему;

4) применением интегрирующего АЦП;

5) тщательной проверкой и наладкой приборов.

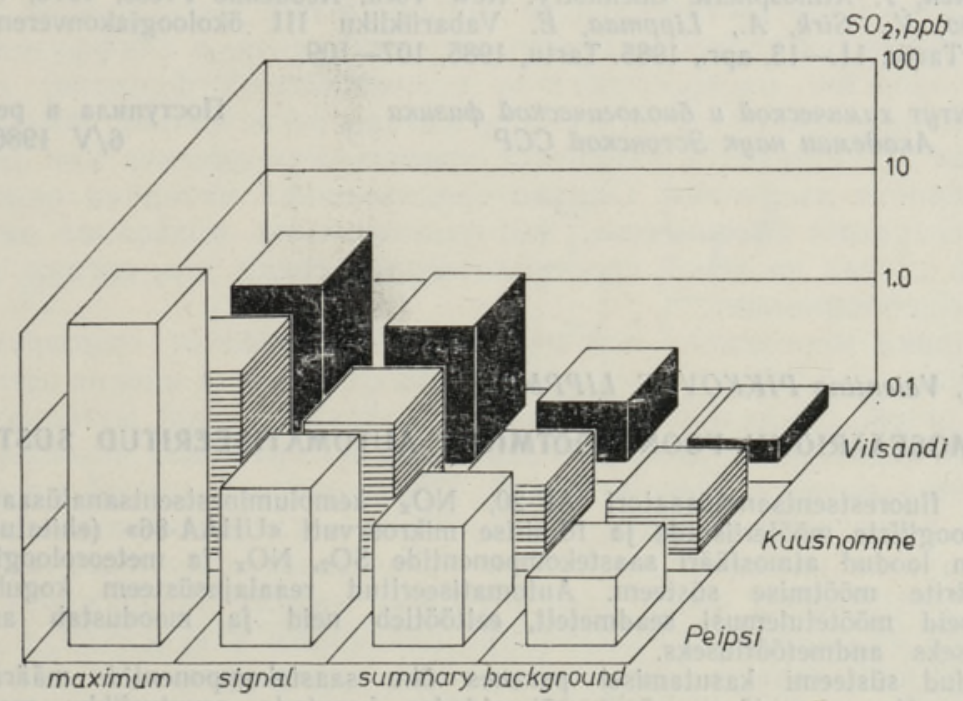

Рис. 3. Результаты полевых измерений концентрации двуокиси серы в разных регионах Әстонской ССР за 1984-1985 гг. 
Полученная чувствительность системы достаточна для измерения природного фона и выделения сигналов выше фона (рис. 2). Таким образом, становится возможным определение природного фона двуокиси серы даже при наличии влияния антропогенных источников, исключением вышефонового сигнала при усреднении данных.

На рис. 3 приведены результаты определения концентрации двуокиси серы в полевых условиях за период 1984-1985 гг. Показаны максимальные десятиминутные, усредненные вышефоновые (сигнальные) и усредненные концентрации двуокиси серы, а также концентрации природного фона двуокиси серы.

\section{4. Выводы}

Использование системы автоматизированного измерения содержания примесей атмосферного воздуха за период 1984-1985 гг. подтвердило ее надежность и эффективность, заключающиеся в следующем:

1) в повышении предельной чувствительности серийных газоанализаторов на один порядок, что позволяет определять природный фон двуокиси серы даже при наличии влияния антропогенных источников;

2) в повышении объема получаемой непрерывной круглосуточной информации, предварительно обработанной в реальном масштабе времени;

3) в возможности оперативного вывода информации на печатающее устройство в виде таблиц и графиков;

4) в составлении банка данных на гибких магнитных дисках для дальнейшего анализа.

\section{Л И ТЕ Р А Т Р А}

1. Pikkov, V., Lippmaa, E. Eesti Loodus, № 11, 690-692 (1985).

2. Robinson, E., Robbins, R. C. J. Air Pollution Control Assoc., 20, 303-306 (1970).

3. Heicklen, J. Atmospheric Chemistry. New York, Academic Press, 1976, 7.

4. Pikkov, V., Sirk, A., Lippmaa, E. Vabariikliku III ökoloogiakonverentsi teesid, Tartu, 11.-13. apr., 1985. Tartu, 1985, 107-109.

Институт химической и биологической физики Академии наук Эстонской ССР

Поступила в редакцию $6 / \mathrm{V} 1986$

\section{A. SIRK, Valentina PIKKOV, E. LIPPMAA}

\section{ATMOSFÄRIOHU FOONIMOOTMISTE AUTOMATISEERITUD SUSTEEM}

$\mathrm{SO}_{2}$ fluorestsentsanalüsaatori AF-20, NO kemoluminestsentsanalüsaatori AC-3, meteoroloogiliste mõõteriistade ja 16-bitise mikroarvuti «UHAA-86» (ehitatud KBFI-s) baasil on loodud atmosfääri saastekomponentide $\mathrm{SO}_{2}, \mathrm{NO}_{\mathbf{x}}$ ja meteoroloogiliste ilmaparameetrite mõõtmise süsteem. Automatiseeritud reaalajasüsteem kogub pidevalt ööpäevaseid mõōtetulemusi seadmetelt, eeltöötleb neid ja moodustab andmepanku edaspidiseks andmetöötluseks.

Loodud süsteemi kasutamisel paranes õhu saastekomponentide määramise piirtundlikkus ühe suurusjärgu võrra, võimaldades kasutada arvutuslikku meetodit $\mathrm{SO}_{2}$ loodusliku fooni määramiseks $\mathrm{ka}$ antropogeensete saasteallikate mōjupiirkonnas. Artiklis on toodud graafikutena $\mathrm{SO}_{2}$ foonì välimõōtmiste tulemused mitmes Eesti NSV piirkonnas aastail 1984-1985. 


\section{AN AUTOMATED AIR MONITORING STATION FOR BACKGROUND MEASUREMENTS}

The article describes an automated air pollution monitoring station based on $\mathrm{SO}_{2}$ fluorescence analyser AF-20, $\mathrm{NO}_{x}$ chemoluminescence analyser $\mathrm{AC}-3$, meteorological instruments and a 16-bit professional microcomputer UHAA-86. Concentrations of pollutant gases $\mathrm{SO}_{2}, \mathrm{NO}_{\mathbf{x}}$ and meteorological data are monitored periodically in real time and recorded into data bank for later analysis.

The system sensitivity for detecting air components is improved by an order of magnitude, which allows to compute the natural background concentration of $\mathrm{SO}_{2}$ even in the presence of sources of pollution. Graphs of experimental backgroundconcentrations of $\mathrm{SO}_{2}$ obtained in various regions of the Estonian SSR in 1984-1985 are presented. 